\title{
Z comme ZOOLOGIE
}

De la reproduction des grenouilles (1758)

\section{Marion Bernard-Schweitzer}

\section{OpenEdition}

\section{Journals}

Édition électronique

URL : https://journals.openedition.org/rbnu/1866

DOI : $10.4000 /$ rbnu. 1866

ISSN : 2679-6104

Éditeur

Bibliothèque nationale et universitaire de Strasbourg

\section{Édition imprimée}

Date de publication : 1 mai 2014

Pagination : 86-87

ISBN : 9782859230524

ISSN : 2109-2761

Référence électronique

Marion Bernard-Schweitzer, "Z comme ZOOLOGIE », La Revue de la BNU [En ligne], 9 | 2014, mis en ligne le 01 mai 2014, consulté le 18 mai 2021. URL : http://journals.openedition.org/rbnu/1866 ; DOI : https://doi.org/10.4000/rbnu.1866

\section{(c) (i) (2)(2)}

La Revue de la BNU est mise à disposition selon les termes de la Licence Creative Commons Attribution - Pas d'Utilisation Commerciale - Partage dans les Mêmes Conditions 4.0 International. 


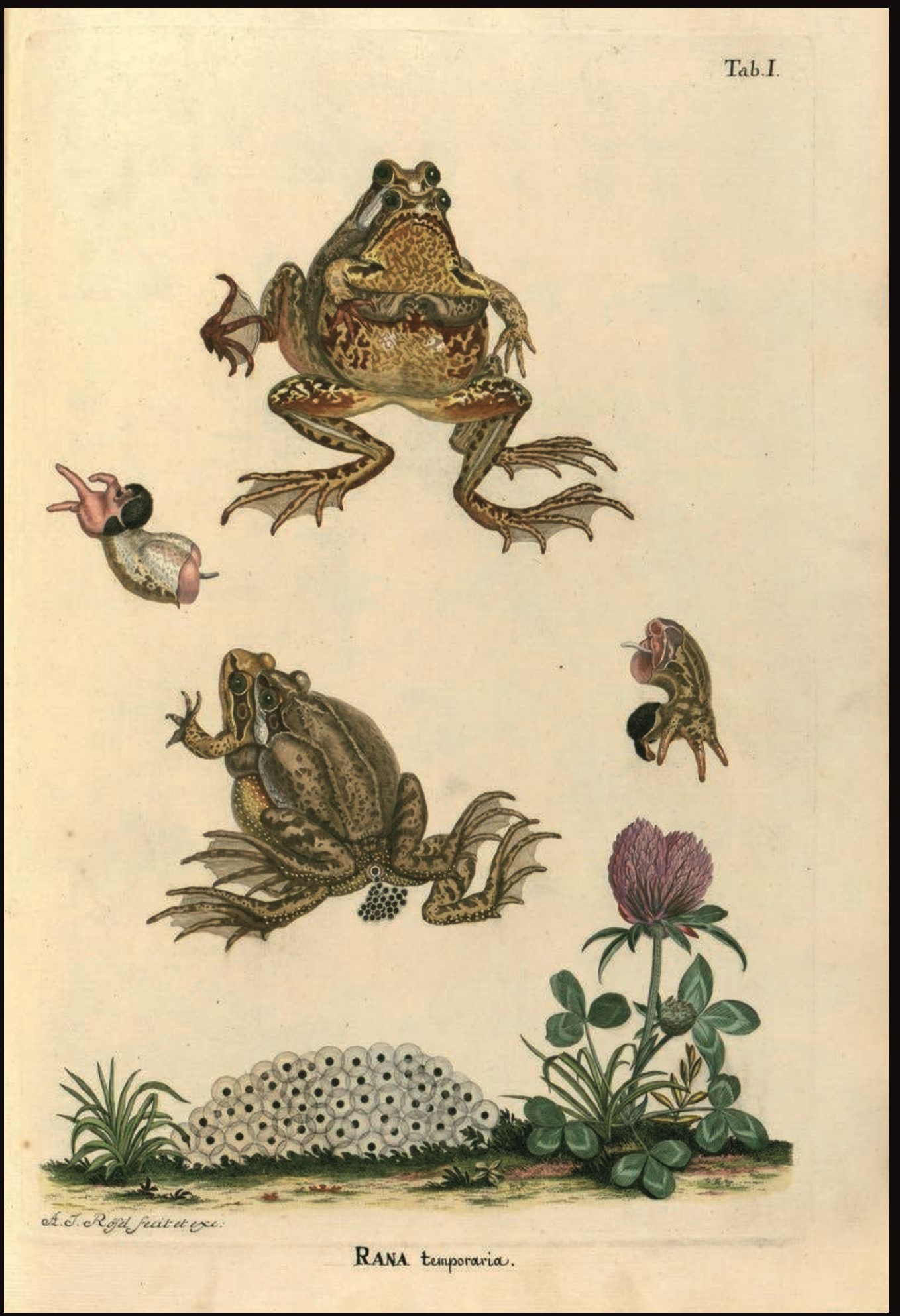


Trésors de l'écrit : un abécédaire

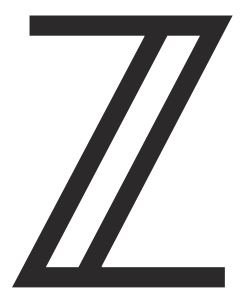

\section{ZOOLOGIE}

\section{De la reproduction des grenouilles (I758)}

Parmi les fonds de sciences exactes de la BNU, conservés depuis 1992 par le Service commun de la documentation de l'Université de Strasbourg, figure sous la cote H.485 un ouvrage remarquable à plusieurs titres. Cette Historia naturalis ranarum nostratium, d'August Johann Rösel von Rosenhof, a été imprimée à Nuremberg, en 1758, par Johann Joseph Fleischmann ${ }^{1}$. Sept sections, d'inégale longueur, composent l'ouvrage; chacune correspond à une espèce de grenouille ou de crapaud connue en Europe : grenouille des champs, rainette verte, grenouille rieuse, ou encore crapaud commun. Au fil de ses cent quinze pages, le texte se déroule sur deux colonnes qui diffèrent tant par la typographie que par la langue employée : au latin les caractères romains, à l'allemand les lettres gothiques, comme il était d'usage à l'époque.

Outre un magnifique frontispice, quarante-huit illustrations en pleine page émaillent ce texte qui traite des batraciens et plus particulièrement de leur reproduction. Témoignant d'une observation minutieuse de cette gent amphibie, les planches, gravées sur cuivre, se déclinent en deux versions : la première, en nuances de gris, comporte des légendes utiles pour le scientifique ; la seconde, ornée de riches coloris, attire davantage l'attention du profane. Les planches, toutes réalisées par Rösel von Rosenhof, représentent les amphibiens, saisis dans leur environnement naturel - une flore vivace et colorée et leurs œufs, tantôt en monticule, tantôt en chapelet. Elles s'attachent également à représenter leur anatomie, avec des reproductions précises de dissection, accompagnées des observations qui en sont déduites. Enfin, des bandeaux gravés sur cuivre par d'autres artistes ornent l'incipit des sept sections ; certains représentent de jolies vues de la ville de Nuremberg au $18^{\text {e }}$ siècle.

L'auteur de cet ouvrage, August Johann Rösel von Rosenhof (1705-1759), est un artiste, peintre de portraits et de miniatures ; passionné par la naturalisation, il publie des ouvrages d'entomologie (il élabore ainsi un classement des insectes qui fait date) qu'il illustre lui-même. Ses observations minutieuses, alliées à son talent d'artiste, font de ses ouvrages, et notamment de celui qui nous occupe, des références en la matière. Pour preuve, la préface de cette édition de 1758, confiée à Albrecht von Haller (1708-1777), médecin et naturaliste suisse, élève du célèbre Boerhaave et dont les compétences en anatomie et physiologie sont reconnues du monde savant de l'époque. Notons que c'est en 1758 , l'année de la parution de cet ouvrage, que le terme " amphibiens " a été introduit par Carl von Linné (1707-1778) dans la classification qu'il établit du monde vivant ${ }^{2}$.

L'ancien possesseur de cet exemplaire est également digne d'être mentionné : l'indication manuscrite " $\mathrm{Bi}$ bliothecae Hammerianae ", portée sur la page de garde, indique qu'il s'agit de Frédéric Louis Hammer (1762-1837), professeur d'histoire naturelle à l'Ecole de pharmacie de Strasbourg et gendre de Jean Hermann (1738-180o), médecin et naturaliste strasbourgeois, dont le cabinet d'histoire naturelle est à l'origine du Musée zoologique de Strasbourg. La bibliothèque de Hermann, enrichie et complétée par Hammer, est actuellement conservée dans les bibliothèques universitaires de Strasbourg.

\section{Marion Bernard-Schweitzer}

\footnotetext{
1 - Une version numérisée de cet exemplaire est consultable sur la bibliothèque numérique du Service commun de la documentation de l'Université de Strasbourg : http://docnum.unistra.fr/cdm/ref/ collection/colli3/id/62338

2 - Voir à ce sujet l'article d'Anna Svenbro, Linné et la France : entre botanique et politique, in La Revue de la BNU, $\mathrm{n}^{\circ}$ 8, 2013
} 